\title{
Prevalence of $\beta$-lactamase production and multi-drug resistance among uropathogenic Escherichia coli isolates at a tertiary care hospital of North-western India
}

\author{
Ruchi Jain ${ }^{1}$, Nita Pal' ${ }^{2}$ Saroj Hooja ${ }^{3}$ \\ ${ }^{1}$ Third Year Resident, ${ }^{2,3}$ Senior Professor, Department of Microbiology, SMS Medical College, Jaipur, Rajasthan, India
}

Background: E.coli is the most common organism causing UTI. Inappropriate and widespread use of broad-spectrum antibiotics has resulted in development of multi-drug resistance and $\beta$-lactamases producing strains. Aims and Objective: To assess $\beta$-lactamase production and multi-drug resistance among uropathogenic E.coli isolates. Materials and Methods: A total of 145 E.coli urinary isolates were included in this study. The isolated organisms were identified by conventional microbiological procedures. Antimicrobial susceptibility was performed by Kirby Bauer disk diffusion method. Isolates were screened for extended spectrum $\beta$-lactamase production and confirmed by phenotypic confirmatory double disc synergy test. Isolates resistant to cefoxitin were considered potential AmpC producers confirmed by AmpC disc test and modified three dimensionsl test. Isolates resistant to imipenem and meropenem were considered potential carbapenemase producers and confirmed by $\mathrm{mCIM}$ test. Results: Out of 145 isolates $91(62.76 \%)$ were isolated from males and $54(37.24 \%)$ from females. Majority of the isolates were obtained from the age group of $21-30$ years $(48.96 \%)$ followed by $31-40$ years $(14.48 \%)$. Highest susceptibility was seen towards fosfomycin $(94.48 \%)$, tigecycline $(87.59 \%)$, nitrofurantoin $(77.24 \%)$. Highest resistance of $81.38 \%$ was observed against ampicillin while more than $70.0 \%$ resistance observed with cefazolin, cefotaxime, ciprofloxacin, levofloxacin and amoxiclav. Multi-drug resistance was observed in $85.51 \%$ isolates and $4.14 \%$ were found to be possible XDR. Among these isolates frequency of Access this article online Website: http://nepjol.info/index.php/AJMS DOI: $10.3126 /$ ajms.v12i7.35046 E-ISSN: 2091-0576 P-ISSN: 2467-9100

Copyright (c) 2021 Asian Journal of Medical Sciences

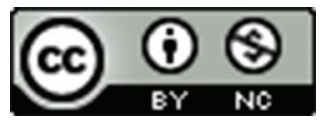

This work is licensed under a Creative Commons Attribution-NonCommercial 4.0 International License. $\beta$-lactamase production was ESBL (45.51\%), AmpC (28.96\%) and carbapenamase (28.96\%). Conclusion: Drug resistance due to $\beta$-lactamases production is emerging as a serious threat in UTI; routine screening of these $\beta$-lactamases will prevent treatment failures.

Key words: $\beta$-lactamases; E.coli; Multi-drug resistant; Urinary tract infection

\section{INTRODUCTION}

Urinary tract infection (UTI) is a term that describes any infection involving any part of the urinary tract, namely the kidneys, ureters, bladder and urethra. UTI can be asymptomatic (subclinical infection) or symptomatic (disease). ${ }^{1}$ Bacteria are the prime agents responsible for causing the infections among humans but the role of certain fungi and viruses cannot be over looked. UTI's are caused by both Gram-negative and Gram-positive bacteria. E.coli is most common organism causing UTI which accounts for up to $90 \%$ of cases followed by Klebsiella spp., Proteus mirabilis, Pseudomonas aeruginosa and Acinetobacterspp. Among gram positive bacteria, Enterococcus spp. is the most common organism responsible for UTI followed by Staphylococcus aureus and Coagulase negative Staphylococci especially Staphylococcus saprophyticus in sexually active females. ${ }^{2}$

Inappropriate and widespread use of antibiotics has led to the emergence of drug resistance mechanisms like the production of extended spectrum $\beta$-lactamases (ESBL), Amp C $\beta$-lactamases and carbapenemases. ${ }^{3}$ 
ESBL are type of $\beta$-lactamases that causes bacterial resistance to the penicillins, first, second and third generation cephalosporins and aztreonam by causing hydrolysis of these antibiotics and which are inhibited by $\beta$-lactamase inhibitors such as clavulanic acid. ${ }^{4} \mathrm{AmpC}$ are a kind of $\beta$-lactamases that are active on cephalosporins and can also hydrolyze cephamycins (cefoxitin and cefotetan); oxyiminocephalosporins such as ceftazidime, cefotaxime and ceftriaxone and monobactams such as aztreonam. Inhibitors such as clavulanic acid, sulbactam and tazobactam have much less effect on AmpC $\beta$ lactamases. ${ }^{5}$ Carbapenem is the drug of choice to treat the infections caused by ESBL producing bacteria. However, in recent decades the emergence of carbapenemase producers that are resistant to the carbapenems are creating global issue in infection control.

The aim of this study was to identify the current prevalence of $\beta$-lactamase producing uropathogenic E.coli and multidrug resistance among them in our hospital.

\section{MATERIALS AND METHODS}

This prospective study was conducted in department of microbiology from June to December 2019. Midstream urine samples were collected from symptomatic patients from both inpatient and outpatient departments. Samples were collected and transferred according to recommended guidelines to prevent contamination.

The urine samples were inoculated on MacConkey's agar and blood agar plates using calibrated loop and incubated aerobically at $37^{\circ} \mathrm{C}$ for 24 hours. Single type of colonies $>10^{5}$ per ml of urine was considered significant. Significant isolates were biochemically characterized by using indole production, citrate utilization, urease production, triple sugar iron agar and motility. ${ }^{6}$ Samples from which significant growth of E.coli was identified were included in the study.

Antibiotic susceptibility was tested by Kirby Bauer disc diffusion method against a panel of antibiotics using bacterial suspension matched to $0.5 \mathrm{McF}$ arland standards as inoculum on Mueller Hinton agar (MHA) (HiMedia Laboratories Pvt. Limited, India). The antibiotics used were Amikacin $(30 \mu \mathrm{g})$, Gentamicin $(10 \mu \mathrm{g})$, Cefoperazonesulbactam $(75+30 \mu \mathrm{g})$, Imipenem $(10 \mu \mathrm{g})$, Meropenem $(10 \mu \mathrm{g})$, Cefazolin $(30 \mu \mathrm{g})$, Cefotaxime $(30 \mu \mathrm{g})$, Cefepime $(30 \mu \mathrm{g})$, Cefoxitin $(30 \mu \mathrm{g})$,Ciprofloxacin $(5 \mu \mathrm{g})$, Levofloxacin $(10 \mu \mathrm{g})$, Trimethoprim + sulphamethoxazole $(1.25+23.7 \mu \mathrm{g})$, Piperacillin+tazobactam $(100 \mu \mathrm{g}+10 \mu \mathrm{g})$, Tigecycline $(15 \mu \mathrm{g})$, Ampicillin $(10 \mu \mathrm{g})$, Amoxicillin+clavulanic acid $(20 \mu \mathrm{g}+10 \mu \mathrm{g})$, Fosfomycin $(200 \mu \mathrm{g}+50 \mu \mathrm{g}$ glucose-6phosphate), Nitrofurantoin $(300 \mu \mathrm{g})$, Tetracycline $(30 \mu \mathrm{g})$ (HiMedia Laboratories Pvt. Limited, India). The zones of inhibition were interpreted according to CLSI guidelines 2019. ${ }^{7}$ E. coli ATCC 25922 was used as control strain. Isolates non-susceptible $\geq 1$ agent in $\geq 3$ antimicrobial categories were considered as multi-drug resistant (MDR); non-susceptible to $\geq 1$ agent in all but $\leq 2$ antimicrobial categories as extensively drug resistant (XDR) and nonsusceptible to $\geq 1$ agent in all antimicrobial categories as pan-drug resistant (PDR). ${ }^{8}$

Screening for ESBL production of E.coli was done by the disc diffusion method. The isolates producing a zone diameter $\leq 27 \mathrm{~mm}$ against cefotaxime $(30 \mu \mathrm{g})$ or zone diameter $\leq 22 \mathrm{~mm}$ against ceftazidime $(30 \mu \mathrm{g})$ were considered as presumptive ESBL producers. These isolates were confirmed by phenotypic confirmatory double disc synergy test (PCDDT). ${ }^{7}$ Isolates showing resistance to cefoxitin (inhibition zone $\leq 18 \mathrm{~mm}$ ) by disc diffusion method were considered potential AmpC producers and further tested by $\mathrm{AmpC}$ disc test and modified three dimensional test. ${ }^{9}$ Isolates showing resistance to imipenem $\&$ meropenem (inhibition zone $\leq 19 \mathrm{~mm}$ ) by disc diffusion method were considered potential carbapenemase producers and further tested by MCIM test (modified carbapenem inactivation method)..$^{7}$ Ethical clearance was obtained from ethical approval committee of the institute.

\section{Statistical analysis}

Statistical analysis was done using computer software statistical package for the social sciences (SPSS) version 20.0. The qualitative data were expressed in proportion and percentages and the quantitative data expressed as mean and standard deviations. The difference in proportion was analyzed by using chi square test. Significance level for tests was determined as $95 \%(\mathrm{P}<0.05)$.

\section{RESULTS}

A total of 145 isolates of E.coli were included in the study. Among these isolates $91(62.76 \%)$ were from male patients and $54(37.24 \%)$ were from female patients. The age group most commonly affected was $21-30$ years $(48.96 \%)$ followed by 31-40 years (14.48\%). Among male patients most of the isolates were obtained from indoor patients $(33.10 \%)$ and among female patients from outdoor patients $(22.06 \%)$ (Table 1).

Ninety seven isolates were screened positive for ESBL production, 66 isolates $(68.04 \%)$ were confirmed as positive by phenotypic confirmatory disc diffusion test (PCDDT). Screening test for Amp C production was positive in 85 isolates, $42(49.41 \%)$ isolates were confirmed by Amp C disc test and modified three dimensional tests. Out of 96 isolates screened positive for carbapenemase production, $42(43.75 \%)$ were confirmed by mCIM test. 
Antibiotic resistance was seen higher among $\beta$-lactamase producers than non $\beta$ - lactamase producers. The difference in resistance between $\beta$-lactamase producers and non $\beta$ - lactamase producers was not significant with cefepime, piperacillin-tazobactam, tigecycline and fosfomycin (Table 2).

The difference in antibiotic resistance pattern among ESBL, AmpC and carbapenemase producing isolates was statistically not significant (Table 3).
Out of 145 isolates 124 isolates $(85.51 \%)$ were found to be multi-drug resistant and 6 isolates $(4.14 \%)$ were found to be possible XDR (Table 2). None of the isolates were pandrug resistant. Multi-drug resistance was observed among all isolates of $\beta$ - lactamase producers and $70.0 \%$ among non $\beta$ - lactamase producers. Among MDR isolates ESBL, Amp C, carbapenemase production was seen in $49.19 \%$, $30.64 \%$, 32.26\% isolates respectively. Coproduction of two $\beta$-lactamases was seen in $48.37 \%$ isolates and all 3 $\beta$ - lactamases were produced together in $7.26 \%$ isolates.

Table 1: Distribution of E. coli isolates in IPD and OPD as per Age Groups and Sex

\begin{tabular}{|c|c|c|c|c|c|c|c|c|c|}
\hline \multirow[t]{2}{*}{ Age Groups in Yrs } & \multicolumn{3}{|c|}{ Male } & \multicolumn{3}{|c|}{ Female } & \multicolumn{3}{|c|}{ Total } \\
\hline & IPD & OPD & Total N (\%) & IPD & OPD & Total N (\%) & IPD & OPD & Total N (\%) \\
\hline$<10$ & 0 & 4 & $4(2.76)$ & 1 & 2 & $3(2.07)$ & 1 & 6 & $7(4.83)$ \\
\hline $11-20$ & 2 & 5 & $7(4.83)$ & 0 & 4 & $4(2.76)$ & 2 & 9 & $11(7.59)$ \\
\hline $21-30$ & 20 & 17 & $37(25.52)$ & 14 & 20 & $34(23.45)$ & 34 & 37 & $71(48.96)$ \\
\hline $31-40$ & 10 & 5 & $15(10.34)$ & 3 & 3 & $6(4.14)$ & 13 & 8 & $21(14.48)$ \\
\hline $41-50$ & 11 & 7 & $18(12.41)$ & 1 & 2 & $3(2.07)$ & 12 & 9 & $21(14.48)$ \\
\hline $51-60$ & 2 & 2 & $4(2.76)$ & 1 & 0 & $1(0.69)$ & 3 & 2 & $5(3.45)$ \\
\hline $61-70$ & 2 & 1 & $3(2.07)$ & 1 & 1 & $2(1.38)$ & 3 & 2 & $5(3.45)$ \\
\hline$>70$ & 1 & 2 & $3(2.07)$ & 1 & 0 & $1(0.68)$ & 2 & 2 & $4(2.76)$ \\
\hline Total & 48 & 43 & $91(62.76)$ & 22 & 32 & $54(37.24)$ & 70 & 75 & $145(100.00)$ \\
\hline
\end{tabular}

Level of significance: at $7 D F_{1}^{*}=0.05$ level of significance $=14.67$, Age and IPD/OPD wise: $\chi_{7}^{2}: 8.129:$ NS $P>0.05$, Age and Gender - wise: $\chi_{7}^{2}: 9.113:$ NS $P>0.05$, IPD/OPD and Gender -wise: $\chi^{2}: 2.329$ : NS $P>0.05$

Table 2: Antibiotic Resistance Pattern of $\beta$ - lactamase Producing E. coli isolates

\begin{tabular}{|c|c|c|c|c|c|}
\hline Antibiotic & $\begin{array}{c}\text { Resistance (145) } \\
\text { N (\%) }\end{array}$ & $\begin{array}{c}\beta \text { - Lactamase } \\
\text { producers }(95) \mathrm{N}(\%)\end{array}$ & $\begin{array}{c}\text { Non } \beta \text { - Lactamase } \\
\text { producers }(50) \mathrm{N}(\%)\end{array}$ & $Z$ value & $P$ value \\
\hline Amikacin & 49 (33.79) & $41(43.15)$ & $8(16.00)$ & $3.37^{\star \star}$ & $<0.01$ \\
\hline Gentamycin & $80(55.17)$ & $63(66.31)$ & $17(34.00)$ & $3.66^{\star \star}$ & $<0.01$ \\
\hline Cefoperazone-sulbactam & $74(51.03)$ & $60(63.15)$ & $14(28.00)$ & $4.00^{* *}$ & $<0.01$ \\
\hline Imipenem & $96(66.20)$ & $83(87.36)$ & $13(26.0)$ & $7.02^{\star \star}$ & $<0.01$ \\
\hline Cefazolin & $107(73.79)$ & 87 (91.57) & $20(40.0)$ & $6.16^{\star \star}$ & $<0.01$ \\
\hline Cefoxitin & $85(58.62)$ & 77 (81.05) & $8(16.0)$ & $7.38^{\star \star}$ & $<0.01$ \\
\hline Cefotaxime & $115(79.31)$ & 85 (89.47) & $30(60.0)$ & $3.85^{\star \star}$ & $<0.01$ \\
\hline Cefepime & $101(69.65)$ & 67 (78.82) & $34(68.0)$ & $1.39^{\mathrm{NS}}$ & $>0.05$ \\
\hline Ceftazidime & $97(66.90)$ & 88 (92.63) & $9(18.0)$ & $8.51^{\star *}$ & $<0.01$ \\
\hline Ciprofloxacin & $110(75.86)$ & 87 (91.57) & $23(46.00)$ & $5.58^{\star \star}$ & $<0.01$ \\
\hline Levofloxacin & $110(75.86)$ & 85 (89.47) & $25(50.00)$ & $4.87^{\star *}$ & $<0.01$ \\
\hline Cotrimoxazole & $90(62.06)$ & 72 (75.78) & $18(36.00)$ & $4.54^{\star *}$ & $<0.01$ \\
\hline Piperacillin-Tazobactam & $48(33.10)$ & $31(32.63)$ & $17(34.00)$ & $0.16^{\mathrm{NS}}$ & $>0.05$ \\
\hline Tigecycline & $18(12.41)$ & $14(14.73)$ & $4(8.00)$ & $1.20^{\mathrm{NS}}$ & $>0.05$ \\
\hline Ampicillin & $118(81.37)$ & $86(90.52)$ & $32(64.00)$ & $3.59^{* *}$ & $<0.01$ \\
\hline Amoxiclav & $110(75.86)$ & 87 (91.57) & $23(46.00)$ & $5.58^{\star *}$ & $<0.01$ \\
\hline Fosfomycin & $8(5.52)$ & $7(7.37)$ & $1(2.0)$ & $1.44^{\mathrm{NS}}$ & $>0.05$ \\
\hline Nitrofurantoin & $33(22.76)$ & $27(28.42)$ & $6(12.0)$ & $2.32^{*}$ & $<0.05$ \\
\hline Tetracycline & $92(63.45)$ & $73(76.84)$ & $19(38.0)$ & $4.45^{\star \star}$ & $<0.01$ \\
\hline Multi-drug resistant (MDR) & $124(85.51)$ & 89 (93.68) & $35(70.0)$ & - & - \\
\hline Possible XDR & $6(4.14)$ & $6(6.31)$ & 0 & - & - \\
\hline
\end{tabular}


Table 3: Antibiotic resistance pattern of ESBL, AmpC and carbapenemase producing E. coli isolates

\begin{tabular}{|c|c|c|c|c|c|}
\hline Antibiotics & $\begin{array}{c}\text { ESBL producers } \\
\mathrm{N}(\%)\end{array}$ & $\begin{array}{c}\text { Amp C producers } \\
\mathrm{N}(\%)\end{array}$ & $\begin{array}{l}\text { Carbapenemase producers } \\
\qquad \mathrm{N}(\%)\end{array}$ & $Z$ value & $P$ value \\
\hline Amikacin & $28(42.42)$ & $21(50.00)$ & $15(35.71)$ & $1.76^{\mathrm{NS}}$ & $>0.05$ \\
\hline Gentamycin & $44(66.66)$ & $32(74.41)$ & $27(64.28)$ & $1.60^{\mathrm{NS}}$ & $>0.05$ \\
\hline Cefoperazone-sulbactam & $42(63.63)$ & 31 (72.09) & $26(61.90)$ & $1.62^{\mathrm{NS}}$ & $>0.05$ \\
\hline Imipenem & $54(81.81)$ & $38(88.37)$ & $42(100.00)$ & $8.98^{\star *}$ & $<0.01$ \\
\hline Cefazolin & $62(93.93)$ & $41(95.34)$ & $37(88.09)$ & $3.13^{\mathrm{NS}}$ & $>0.05$ \\
\hline Cefoxitin & $54(81.81)$ & $42(100.00)$ & 32 (76.19) & $10.68^{\star \star}$ & $<0.01$ \\
\hline Cefotaxime & $58(87.87)$ & $39(92.85)$ & 38 (90.47) & $0.72^{\mathrm{NS}}$ & $>0.05$ \\
\hline Cefepime & 46 (69.69) & $30(71.42)$ & $25(59.52)$ & $1.65^{\mathrm{NS}}$ & $>0.05$ \\
\hline Ceftazidime & $66(100.00)$ & $40(95.23)$ & 36 (85.71) & $10.41^{* *}$ & $<0.01$ \\
\hline Ciprofloxacin & $57(86.36)$ & $38(90.47)$ & $41(97.61)$ & $3.84^{\mathrm{NS}}$ & $>0.05$ \\
\hline Levofloxacin & $58(87.87)$ & 37 (88.09) & $40(95.23)$ & $1.78^{\mathrm{NS}}$ & $>0.05$ \\
\hline Cotrimoxazole & 52 (78.78) & $33(76.74)$ & $30(71.42)$ & $0.90^{\mathrm{NS}}$ & $>0.05$ \\
\hline Piperacillin-Tazobactam & $41(62.12)$ & $28(65.11)$ & $27(64.28)$ & $0.23^{\mathrm{NS}}$ & $>0.05$ \\
\hline Tigecycline & $11(16.66)$ & $8(19.04)$ & $6(14.28)$ & $0.34^{\mathrm{NS}}$ & $>0.05$ \\
\hline Ampicillin & $58(87.87)$ & $38(90.47)$ & $39(92.85)$ & $0.72^{\mathrm{NS}}$ & $>0.05$ \\
\hline Amoxiclav & $58(87.87)$ & $39(92.85)$ & 34 (80.95) & $2.72^{\mathrm{NS}}$ & $>0.05$ \\
\hline Fosfomycin & $4(6.06)$ & $5(11.63)$ & $0(0.00)$ & $5.27^{\mathrm{NS}}$ & $>0.05$ \\
\hline Nitrofurantoin & $20(30.30)$ & $12(28.57)$ & $12(28.57)$ & $0.05^{\mathrm{NS}}$ & $>0.05$ \\
\hline Tetracycline & 49 (74.24) & 36 (85.71) & $33(78,57)$ & $2.01^{\mathrm{NS}}$ & $>0.05$ \\
\hline
\end{tabular}

NS=Not Significant, $*=$ Significant at 0.05 level of significance, $* *=$ Significant at 0.01 level of significance, 0.05 level of significance $=5.991$ and 0.01 level of significance $=9.210$

\section{DISCUSSION}

Urinary tract infections represent one of the most common diseases encountered in the routine clinical practice, with an estimated 150 million UTIs per annum worldwide. The predominant uropathogens for UTIs are gram negative bacteria with E.coli accounting for the highest prevalence in most instances. ${ }^{10}$ In our study there was male preponderance of $62.76 \%$ for this infection while in females it was $37.24 \%$. This male preponderance could be due to the fact that the samples were received from departments other than obstetrics and gynaecology. Age group analysis revealed that significant numbers of E.coli were isolated from age group of $21-40$ years $(63.44 \%)$ in both males $(35.86 \%)$ and female patients $(27.59 \%)$, similar observation was seen in studies by Bakshi R et al. $(77.35 \%),{ }^{11}$ Rahman MS et al. $(56.0 \%),{ }^{2}$ Shakya P et al. $(42.19 \%),{ }^{12}$ Sahu RK et al $(40.85 \%)^{13}$ and Das B et al $(58.84 \%) .{ }^{14}$

Increasing rates of $\beta$-lactamase producing bacteria are causing serious UTI in the society and hospitals world-wide. In our study ESBL production was observed in $45.51 \%$ of E.coli isolates which is in concordance with findings in many studies from different parts of India., ${ }^{3,11,15,19}$ In the current study, the Amp C production was seen in $28.96 \%$ (42/145) isolates, similar finding has been reported by Bora A et $a .^{20}$ from Assam. Compared to these findings other studies have reported a lower prevalence of the AmpC producers. ${ }^{1,11,16,17,19,21,22}$ while Shreshtha UT et al. ${ }^{23}$ reported a higher prevalence of $46.3 \%$. Prevalence of coproduction of AmpC among ESBL isolates in the present study was $42.86 \%$, which is higher than Gupta $\mathrm{V}$ et al.8.0\%, ${ }^{16} \mathrm{Mwinga}$ MM et al. $10.77 \%{ }^{24}$ and Shreshtha UT et al.19.4\%. ${ }^{23}$
Prevalence of carbapenamase producing E.coli isolates in the present study was $28.96 \%$. Varied prevalence was observed in other studies; Shreshtha UT et al. $(11.2 \%){ }^{23}$ Mwinga MM et al (18.4\%). ${ }^{24}$ No significant difference was seen between $\beta$-lactamases producing isolates from outpatients and in-patients $(\mathrm{P}=>0.05)$.

Significant difference in antibiotic resistance pattern was found between $\beta$-lactamase and non $\beta$-lactamase producers in our study. Among $\beta$-lactamase producers fosfomycin resistance was lowest (7.37\%). Low resistance to fosfomycin has also been observed by Das B et al. $(7.7 \%)^{14}$ and Rahman MS et al. $(4.0 \%){ }^{2}$ In few studies all the $\beta$-lactamase producing isolates were found to be susceptible to fosfomycin. ${ }^{11,16}$ Resistance to nitrofurantoin in most studies was in the range of $10-20 \% .^{11,14,18,19}$ In our study and Ranjini CY et al. ${ }^{3}$ nitrofurantoin resistance was seen in $28.42 \%$ and $26.77 \%$ isolates respectively while Gupta $\mathrm{V}$ et al. ${ }^{16}$ found no resistance. The ICMR, antimicrobial resistance surveillance network, 2018 data has reported $88.1 \%$ and $86.0 \%$ of the isolates to be sensitive to two old antibiotics, fosfomycin and nitrofurantoin respectively. ${ }^{25}$ In most of the studies no resistance to imipenem was observed $^{14,16,19}$ but we have observed a high resistance of $66.21 \%$. Chauhan S et al. ${ }^{19}$ and Das B et al. ${ }^{14}$ found no resistance to tigecycline while in this study $14.73 \%$ isolates were resistant. Varied range of resistance to amikacin was reported: $6.0 \%$ to $55.0 \% .^{3,11,16,18,19}$ Moderate resistance to piperacllin-tazobactam was found in the present study $(32.63 \%)$ and Chauhan $\mathrm{S}$ et al. ${ }^{17}$ reported $46.0 \%$, however most authors found a low resistance of $5-16 \%{ }^{2,11,14,16}$ Resistance to co-trimoxazole, ampicillin and fluoroquinolones was high in most of the studies. 
Among non $\beta$-lactamase producing isolates fosfomycin was least resistant $(2.0 \%)$ followed by tigecycline $(8.0 \%)$, nitrofurantoin $(12.0 \%)$, amikacin and cefoxitin $(16.0 \%)$, ceftazidime $(18.0 \%)$.

In this study we have observed good susceptibility with fosfomycin, tigecycline and nitrofurantoin among both $\beta$-lactamase and non $\beta$-lactamase producing isolates. Resistance to cefepime, piperacillin-tazobactam, tigecycline and fosfomycin among $\beta$-lactamase and non $\beta$-lactamase producing isolates was statistically insignificant. All $\beta$-lactamase producing isolates were found to be MDR in the present and in other studies. ${ }^{3,11,14,16}$

\section{CONCLUSION}

In the majority of UTI cases, antibiotics are given empirically before bacteriology culture results are available. The $\beta$-lactam antibiotics are among the most frequently prescribed antibiotics world-wide, the selective pressures created by the indiscriminate use of the $\beta$-lactam antibiotics have led to the selection of a variety of mutant forms of $\beta$-lactamases such as the ESBL, AmpC and carbapenemase. The genes for $\beta$-lactamases are usually found on R-plasmids encoding resistance to aminoglycosides, sulfonamides, tetracyclines and other antibiotics. Therefore, the infections caused by $\beta$-lactamases producing bacteria pose serious treatment challenges. Information on prevailing levels of antimicrobial resistance in this study would help clinicians to be aware of the reasons of treatment failures caused by serious infections due to these bacteria and guide for appropriate empirical antimicrobial therapy.

To combat the prevalence of antimicrobial resistance, strict antibiotic policies to limit the indiscriminative use of cephalosporins and carbapenems in the hospital and effective infection control measures like hand washing and barrier precautions should be implemented.

\section{REFERENCES}

1. Tan CW and Chlebicki MB. Urinary tract infections in adults. Singapore Med J.2016; 57:485-490.

https://doi.org/10.11622/smedj.2016153

2. Rahman MS, Garg R, Singh VA and Biswas D. Antibiotic susceptibility profile and extended spectrum $\beta$-lactamases production by uropathogenic Escherichia coli from tertiary care hospital of rural settings. Int J Res Med Sci. 2018; 6:4022-4027. https://doi.org/10.18203/2320-6012.ijrms20184901

3. Ranjini CY, Kasukurthi LR, Madhumati B and Rajendran R. Prevalence of multidrug resistance and extended spectrum beta-lactamases among uropathogenic Escherichia coli isolates in a tertiary care hospital in South India: An alarming trend. Community Acquir Infect. 2015; 2:19-24.

https://doi.org/10.4103/2225-6482.153861
4. Paterson DL and Bonomo RA. Extended-Spectrum $\beta$-Lactamases: a Clinical Update. Clin Microbiol Rev. 2005; 18(4): 657-686.

https://doi.org/10.1128/CMR.18.4.657-686.2005

5. Jacoby GA. AmpC $\beta$-Lactamases. ClinMicrobiol Rev.2009; 22:161-182.

https://doi.org/10.1128/CMR.00036-08

6. Procop WG, Church LD, Hall SG, Janda MW, Koneman WE, Shreckenberger CP, Woods LG. Koneman's Color Atlas \&Textbook of Diagnostic Microbiology, 7th ed. Lippincott Williams and Wilkins;2016.

7. Clinical and Laboratory Standards Institute (CLSI).Performance Standards for Antimicrobial Susceptibility Testing;Twenty nine informational supplement 2019;39:M100-S29.

https://clsi.org/standards/products/microbiology/documents/ m100-preorder/

8. Magiorakos AP, Srinivasan A, Carey RB, Carmeli Y, Falagas ME, Giske CG, et al. Multidrugresistant, extensively drugresistant and pandrugresistant bacteria: An international expert proposal for interim standard definitions for acquired resistance. ClinMicrobiol Infect.2012;18:268281.

https://doi.org/10.1111/j.1469-0691.2011.03570.x

9. Singhal S, Mathur T, Khan S, Upadhyay DJ, Chugh S, Gaind R, et al. Evaluation of Methods for AmpC Beta-Lactamase in Gram Negative Clinical Isolates from Tertiary Care Hospitals. IJMM. 2005; 23:120-124.

https://doi.org/10.4103/0255-0857.16053

10. Wadekar MD, Jagdish L, Swaroopa RNB and Gupta RK. Extended spectrum $\beta$ lactamase- producing Escherichia coli in urinary tract infections tip-off to evaluate treatment practice. IJMR. 2016;3(2):175-179.

https://doi.org/10.5958/2394-5478.2016.00040.6

11. Bakshi R, Sehgal VK, Kansal $P$ and Kaur $S$. Detection of Extended-Spectrum Beta Lactamases and AmpC Beta Lactamases Producing Uropathogenic Escherichia coli in a TertiaryCareHospital.IJMDS.2019;8(2):1783-1792. https://doi.org/10.18311/ijmds/2019/23503

12. Shakya P, Shreshtha D, Maharjan E, Sharma VK and Paudyal R. ESBL Production Among E. coli and Klebsiella spp. Causing Urinary Tract Infection: A Hospital Based Study. Open Microbiol J.2017; 11:23-30. https://doi.org/10.2174/1874285801711010023

13. Sahu RK, Pradhan S, Sao S, Murthy R, Agrawal E, Patel A and Pandey N. Isolation and identification of various Extended Spectrum Beta-Lactamase producing uropathogens in a tertiary care hospital, Chhattisgarh. Int J Res Pharm Sci. 2019;10(4):3244-3250.

https://doi.org/10.26452/ijrps.v10i4.1629

14. Das B, Mittal N, Goswami R, Adhana D and Rathore N. Prevalence of multidrug resistance (MDR) and extended spectrum betalactamases (ESBLs) among uropathogenic Escherichia coli isolates from female patients in a tertiary care hospital in North India. IJRCOG. 2018; 7:5031-5036. https://doi.org/10.18203/2320-1770.ijrcog20184961

15. Aggarwal R, Chaudhary $U$ and Sikka R. Detection of Extended Spectrum $\beta$-lactamase Production Among Uropathogens. JLP.2009; 1:7-10. https://doi.org/10.4103/0974-2727.44423

16. Gupta V, Rani H, Singla N, Kaistha N and Chander J. Determination of extended-spectrum $\beta$-lactamases and AmpC production in uropathogenic isolates of Escherichia coli and susceptibility to fosfomycin.JLP.2013;5:90-93. https://doi.org/10.4103/0974-2727.119849 
17. Aruna $\mathrm{K}$ and Mobashshera T. Prevalence of extended spectrum beta lactamase production among uropathogens in south Mumbai and its antibiogram pattern. EXCLI J. 2012:363-372. http://excli.de/vol11/Aruna07_2012/Aruna06072012_proof.pdf

18. Mukherjee $M$, Basu S, Mukherjee SK and Majumder M. Multidrug-Resistance and Extended Spectrum Beta-Lactamase Production in Uropathogenic E.coli which were Isolated from Hospitalized Patients in Kolkata, India. J Clin Diagn Res. 2013;3:449-453.

https://doi.org/10.7860/JCDR/2013/4990.2796

19. Chauhan S, Mahawal BS and Ramola DC. Extended spectrum $\beta$-lactamases in urinary isolates of Escherichia coli - prevalence and susceptibility pattern at a tertiary care hospital. Int J Res Med Sci. 2015; 3:1622-1626.

https://doi.org/10.18203/2320-6012.jirms20150240

20. Bora A, Ahmed GU and Hazarika NK .Phenotypic detection of extended spectrum $\beta$-lactamase and AmpC $\beta$-lactamase in urinary isolates of Escherichia coli at a tertiary care referral hospital in Northeast India. JCMS Nepal.2012; 8:1-8. https://doi.org/10.3126/jcmsn.v8i3.8682

21. Grover N, Sahni AK and Bhattacharya S. Therapeutic challenges of ESBLS and AmpC beta-lactamase producers in a tertiary care center. Med J Armed Forces India.2012; 69:4-10.

https://doi.org/10.1016/j.mjafi.2012.02.001

22. Amatullah F, Pavani $G$ and Nandeshwar AJ. Detection of ESBLs, MBLs and AmpCs in Gram Negative Uropathogens in Tertiary Care Hospital. IJCMAS.2017; 6: 1594-1604. https://doi.org/10.20546/ijcmas.2017.611.191

23. Shrestha UT, Shrestha S, Adhikari N, Rijal KR, Shrestha B, Adhikari $B$, et al. Plasmid profiling and occurrence of $\beta$-lactamase enzymes in multidrug-resistant uropathogenic Escherichia coli in Kathmandu, Nepal. Infect Drug Resist. 2020; 13:1905-1917. https://doi.org/10.2147/IDR.S250591

24. Mwinga MM, Mahale RP and MN Sumana. Phenotypic detection of AmpC $\beta$ lactamase and metallo $\beta$ lactamase production among uropathogenic E.coli. IJSR.2018; 7:68-71. https://www.doi.org/10.36106/ijsr

25. Walia K, Ohri V, Singh H, Madhumathi J and Kaur J. Annual report antimicrobial resistance surveillance network, ICMR, 2018.

http://iamrsn.icmr.org.in/

\section{Author's Contribution:}

RJ - Concept and design of study, acquisition of data and analysis, final approval of the version to be published; NP - Concept and design of study, acquisition of data and analysis and interpretation of data, drafting the article, final approval of the version to be published; SH - Drafting the article, revising it critically for important intellectual content, final approval of the version to be published.

\section{Work Attributed to:}

Department of Microbiology, SMS Medical College, Jaipur, Rajasthan, India.

\section{Orcid ID:}

Dr. Ruchi Jain - id https://orcid.org/0000-0003-1976-5348

Dr. Nita Pal - ib https://orcid.org/0000-0003-3179-7924

Dr. Saroj Hooja - (1) https://orcid.org/0000-0002-4568-3891 